\title{
KETERBUKAAN PERDAGANGAN DAN SKILL PREMIUM : BUKTI EMPIRIS DI INDONESIA
}

\author{
Noorish Heldini \\ Departemen Ilmu Ekonomi, Universitas Indonesia, Depok, Indonesia \\ nheldini@gmail.com
}

\begin{abstract}
This paper examines the impact of trade openness on premium skills based on technology intensity. Trade openness in this study was measured by foreign investment (FDI). Generally, FDI binds with the technology used in the country of origin. When FDI comes from developed countries with higher level of technology to developing countries with lower levels of technology, developing countries will adopt more advance technology. Because technology is generally complemented by skilled workers, FDI from countries with higher technology causes changes in the structure of labor demand, where the demand for skilled labor is higher than unskilled labor (rising in premium skills). This study took into account the intensity of the technology used because it was suspected that the intensity of the technology has different impacts between companies. To prove the hypothesis, this study used company level data in the manufacturing sector for 2003-2015. The results of FE-IV showed that companies that receive a minimum of 10 percent foreign investment have higher premium skills, both firms that are in the high-tech industry as well as in the low-tech industry.
\end{abstract}

Keywords: wage inequalities, trade openness, Foreign Direct Investment (FDI)

\begin{abstract}
Abstrak
Penelitian ini bertujuan mengestimasi dampak keterbukaan perdagangan terhadap skill premium bedasarkan intensitas teknologi. Keterbukaan perdagangan dalam penelitian ini diukur dengan investasi asing (FDI). FDI umumnya ikut membawa teknologi yang digunakan di negara di negara asal. Ketika investasi asing masuk dari negara maju yang memiliki tingkat teknologi lebih tinggi ke negara berkembang yang memiliki tingkat teknologi lebih rendah, negara berkembang akan mengalami peningkatan teknologi. Karena teknologi umumnya berkomplementer dengan tenaga kerja ahli, masuknya investasi asing dari negara yang memiliki teknologi lebih tinggi menyebabkan perubahan struktur permintaan tenaga kerja dimana permintaan tenaga kerja ahli lebih tinggi dari tenaga kerja tidak ahli (skill premium naik). Penelitian ini ikut mempertimbangkan intensitas teknologi yang digunakan karena diduga intensitas teknologi membawa dampak yang berbeda antar perusahaan. Untuk menjawab hal tersebut, penelitian ini Menggunakan data level perusahaan sektor manufaktur tahun 2003-2015, hasil FE-IV menunjukkan bahwa dampak keterbukaan perdagangan melalui variable FDI menunjukkan bahwa perusahaan yang menerima investasi asing minimal 10 persen memiliki skill premium yang lebih tinggi, baik perusahaan yang berada di industri berintensitas teknologi tinggi maupun industri berintensitas teknologi rendah.
\end{abstract}

Kata kunci : ketimpangan upah, keterbukaan perdagangan, investasi asing

\section{Pendahuluan}

Keterbukaan ekonomi merupakan salah satu penyebab ketimpangan pendapatan antar tenaga kerja (asumsi tenaga kerja dibedakan menjadi tenaga kerja ahli dan tenaga kerja tidak ahli) di negara berkembang. Menurut Acemoglu (1998), perubahan teknologi tidak terjadi secara natural melainkan di-design oleh tenaga kerja ahli, oleh karena itu perubahan teknologi umumnya bersifat komplementer dengan tenaga kerja ahli. Akibatnya, ketika suatu negara melakukan perdagangan dengan negara yang memiliki teknologi lebih tinggi 
dimana teknologi tersebut berkomplementer dengan tenaga kerja ahli, perusahaan akan meminta tenaga kerja ahli lebih tinggi daripada tenaga kerja tidak ahli (ketimpangan pendapatan tenaga kerja tinggi). Sebaliknya, ketika mobilitas faktor produksi berasal dari negara yang memiliki tingkat teknologi yang berkomplementer dengan tenaga kerja tidak ahli, perusahaan akan meminta tenaga kerja tidak ahli lebih tinggi dibandingkan tenaga kerja ahli (ketimpangan pendapatan antar tenaga kerja rendah). Namun ketika mobilitas faktor produksi berasal dari negara yang memiliki tingkat teknologi yang sama, struktur permintaan tenaga kerja tidak berubah (tetap) sehingga tidak merubah pendapatan antar tenaga kerja.

Bedasarkan teori ekonomi, dampak keterbukaan perdagangan terhadap skill premium masih menjadi perdebatan. Bedasarkan teori Stolper-Samuelson, keterbukaan ekonomi menyebabkan peningkatan terhadap faktor-faktor abundant di suatu negara. Selanjutnya Goldberg \& Pavcnik (2007) dan Meschi et al. (2011) mengasumsikan negara berkembang memiliki faktor abundant yaitu tenaga kerja tidak ahli sehingga keterbukaan perdagangan menyebabkan permintaan terhadap tenaga kerja tidak ahli lebih tinggi dibandingkan tenaga kerja ahli (skill premium turun). Namun teori stopler-samuelson mengasumsikan teknologi antar negara sama, ketika perdagangan dilakukan oleh negara yang memiliki tingkat teknologi yang berbeda maka dampaknya kemungkinan bisa berbeda. Menurut Feenstra, \& Hanson (2005), keterbukaan perdagangan menyebabkan ketimpangan upah baik di negara penghasil teknologi maupun negara penerima. Negara penghasil teknologi akan meningkatkan permintaan tenaga kerja ahli dikarenakan negara maju akan berupaya meningkatkan aktivitas R\&D sehingga permintaan tenaga kerja ahli pada negara yang terbuka ekonominya akan lebih besar. Sedangkan negara penerima teknologi juga cenderung meningkatkan permintaan tenaga kerja ahli karena terjadi transfer teknologi dimana diasumsikan teknologi tersebut berkomplementer dengan tenaga kerja ahli sehingga permintaan tenaga kerja diutamakan kepada tenaga kerja yang mampu mengadopsi teknologi.

Menurut literature, salah satu proxy keterbukaan perdagangan adalah masuknya investasi asing (FDI). FDI merupakan salah satu cara masuknya kapital dan transfer teknologi ke negara berkembang dan menjadi indikator terjadinya perkembangan teknologi di negara berkembang (Lee \& Wie, 2015). Investasi asing (FDI) masuk melalui perusahaan multinasional dimana perusahaan multinasional tersebut ikut membawa teknologi yang biasa digunakan di negara asal (Bandick \& Hansson, 2009). Ketika investasi asing masuk dari negara maju yang memiliki teknologi lebih tinggi ke negara berkembang, masuknya investasi tersebut menyebabkan perubahan teknologi di negara berkembang (Meschi, Taymaz, \& Vivarelli, 2011). Ketika teknologi berkomplementer dengan tenaga kerja ahli, perusahaan akan meminta tenaga kerja yang mampu mengadopsi teknologi (tenaga kerja ahli), disisi lain tenaga kerja yang tidak mampu mengadopsi teknologi akan berkurang permintaannya (tenaga kerja tidak ahli). Selain itu, keberadaan perusahaan asing yang mampu memberikan upah yang lebih besar akan faktor penarik bagi tenaga kerja ahli Tenaga kerja ahli yang memiliki kemampuan mengadopsi teknologi akan cenderung pindah ke perusahaan yang mampu memberikan upah yang lebih besar (Bandick \& Hansson, 2009) (Lipsey \& Sjoholm, 2001).

Perbedaan intensitas teknologi pada perusahaan menyebabkan dampak keterbukaan perdagangan terhadap skill premium dapat bersifat heterogen. Menurut Charfeddine \& Mrabet (2015), perusahaan berada di sektor yang memiliki intensitas teknologi tinggi cenderung menggunakan teknologi dalam proses produksinya. Dengan asumsi teknologi berkomplementer dengan tenaga kerja ahli, perusahaan cenderung lebih efisien jika perusahaan mempekerjakan tenaga kerja ahli lebih tinggi. Sebaliknya, perusahaan yang berada di sektor berintensitas teknologi rendah maka perusahaan cenderung menggunakan teknologi yang berkomplementer dengan 
tenaga kerja tidak ahli sehingga permintaan tenaga kerja tidak ahli lebih tinggi relatif terhadap tenaga kerja ahli. Perbedaan intensitas teknologi perusahaan menyebabkan dampak keterbukaan perdagangan terhadap skill premium bisa berbeda. Oleh karena itu penting untuk mengikutsertakan tingkat teknologi dalam mengukur dampak keterbukaan perdagangan terhadap skill premium dengan membedakan intensitas teknologi pada setiap sektor perusahan manufaktur.

Penelitian empiris terhadap dampak investasi asing (FDI) menunjukan dampak yang berbeda pada ketimpangan pendapatan antar tenaga kerja. FDI pada awalnya meningkatkan ketimpangan namun semakin lama ketimpangan akan semakin berkurang di Irlandia (Figini \& Görg, 1998). Penelitian lainnya menunjukan bahwa FDI tidak signifikan mempengaruhi ketidakmerataan upah namun apabila diestimasi pada level masing-masing negara dampak FDI berbedabeda, dimana FDI di negara Hong Kong dan Philippina berpengaruh negatif terhadap skill premium (ketimpangan pendapatan antar tenaga kerja rendah) sedangkan di Thailand berpengaruh positif terhadap skill premium (ketimpangan pendapatan antar tenaga kerja tinggi) (te Velde \& Morrissey, 2004). Selanjutnya penelitian di 48 negara US pada 1977-2001 menunjukan 27 negara menunjukan dampak FDI menurunkan ketimpangan, sedangkan 21 negara menunjukan sebaliknya yaitu dampak FDI justru meningkatkan ketimpangan (Taylor \& Driffield, 2005).

Bedasarkan teori dan empiris, ketika menganalisa keterbukaan perdagangan terhadap skill premium, penelitian menjadi bias. Perubahan skill premium tidak hanya dipengaruhi oleh FDI tetapi juga intensitas teknologi perusahaan. Apakah dampak investasi asing terhadap skill premium bersifat heterogen tergantung dari intensitas teknologi perusahaan? Untuk menjawab pertanyaan tersebut, maka penelitian ini bertujuan menganalisis dampak masuknya investasi asing terhadap skill premium bedasarkan intensitas teknologi pada setiap perusahaan di Indonesia. Penelitian ini menarik karena saat ini Indonesia sedang melakukan revolusi indutri menuju industri 4.0. Proses industrialisasi tersebut berpotensi menyebabkan perubahan struktur industri yang lebih bersifat high technology (Abramovitz, 1993). Untuk membuktikan secara empiris, penelitian ini menggunakan data panel periode 2003-2015 dengan menganalisis investasi asing terhadap skill premium. Selain itu untuk menangkap perbedaan intensitas teknologi, penelitian ini membentuk satu dummy variabel bedasarkan sektor 3 digit ISIC. Ketika perusahaan berada di industri berintensitas teknologi rendah maka diberi nilai 0 (nol) sedangkan ketika perusahaan berada di industri berintensitas teknologi rendah diberi nilai 1 (satu).

Penelitian ini mengukur skill premium sebagai rasio pendapatan antara tenaga kerja ahli dan tenaga kerja tidak ahli. Tenaga kerja ahli diproksi dengan tenaga kerja nonproduksi sedangkan tenaga kerja tidak ahli diproksi dengan tenaga kerja produksi. Keterbatasan penelitian ini adalah tenaga kerja tidak dibedakan antara tenaga kerja lakilaki dan perempuan. Selain itu, penelitian hanya melihat perubahan tenaga kerja dari sisi perusahaan (labor demand) akibat keterbukaan perdagangan terhadap skill premium. Penelitian ini memiliki beberapa unsur kebaruan yaitu melihat pengaruh FDI terhadap skill premium bedasarkan intensitas teknologi. Untuk menjawab hal tersebut, peneliti menggunakan data survey industri besar dan sedang yang di peroleh dari Badan Pusat Statistik (BPS) periode 2003-2015. Data tersebut diestimasi dengan menggunakan FEIV karena diduga perusahaan membutuhkan waktu dalam merespon kebijakan keterbukaan perdagangan sehingga peneliti menggunakan lag skill premium sebagai variable exsogen. Hasilnya menunjukkan bahwa perusahaan yang memiliki investasi asing memiliki skill premium lebih tinggi, namun dampak tersebut homogen antar perusahaan yang berbeda intensitas teknologi.

\section{Metode Penelitian}

Keberadaan FDI merupakan salah satu penyebab perubahan teknologi di negara 
berkembang. Lee \& Wie (2015) berpendapat bahwa FDI merupakan salah satu cara perpindahan kapital dan teknologi ke negara berkembang dan merupakan salah satu indikator terjadinya perkembangan teknologi di negara berkembang. Hal tersebut dikarenakan investasi asing umumnya ikut membawa teknologi yang digunakan di negara asal (Bandick \& Hansson, 2009). Ketika investasi asing masuk dari negara maju yang memiliki intensitas teknologi lebih tinggi masuk ke negara berkembang yang memiliki intensitas teknologi lebih rendah, perusahaan lokal di negara berkembang berupa mengadopsi teknologi dari perusahaan asing sehingga terjadi peningkatan teknologi di negara berkembang (Kokko, Zejan, \& Tansini, 2001; Marin \& Bell, 2006).

Peningkatan teknologi di negara berkembang menyebabkan perubahan struktur permintaan dan upah antar tipe

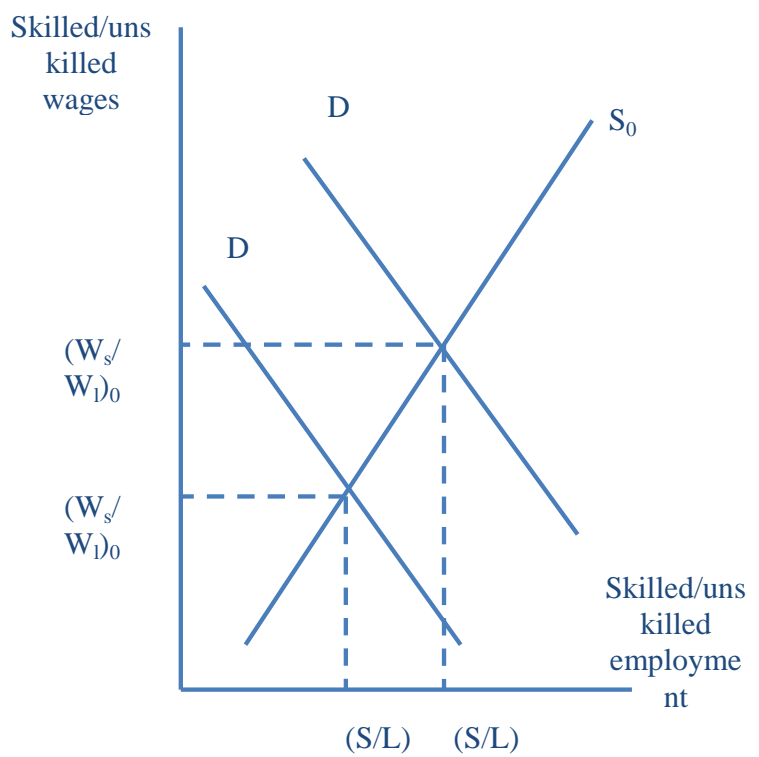

Gambar 1

Dampak Perubahan Teknologi terhadap Rasio Upah Tenaga Kerja

Sumber : (Berman et al., 2003) tenaga kerja. Menurut Berman et al., 2003, kenaikan upah dan tenaga kerja ahli dapat dijelaskan dalam kurva supply dan demand tenaga kerja dimana tenaga kerja ahli dan tenaga kerja tidak ahli diasumsikan dibayar sesuai dengan marginal produknya. Ketika terjadi perubahan teknologi, kurva permintaan mengalami pergeseran. Dengan asumsi supply tetap, pergeseran kurva permintaan menyebabkan kenaikan rasio tenaga kerja dan upah antara tenaga kerja ahli terhadap tenaga kerja tidak ahli. Peningkatan rasio tenaga kerja dan upah disebabkan teknologi baru mampu meningkatkan produktivitas tenaga kerja yang mampu menguasai teknologi sehingga perusahaan akan meningkatkan permintaan tenaga kerja yang mampu menggunakan teknologi. Penjelasan dapat dilihat pada gambar 1 . 
jumlah tenaga kerja ahli terhadap tidak ahli (asumsi supply tetap) sehingga keseimbangan berada di titik potong $(\mathrm{S} / \mathrm{L})_{1}$ dan $\left(\mathrm{Ws} / \mathrm{W}_{\mathrm{L}}\right)_{1}$ dengan rasio upah dan rasio tenaga kerja yang lebih tinggi.

Dampak perubahan teknologi terhadap perubahan struktur permintaan tenaga kerja tergantung pada intensitas teknologi yang digunakan perusahaan. Penelitian Charfeddine \& Mrabet (2015) mengungkapkan bahwa setiap sektor memiliki intensitas teknologi yang berbeda sehingga dampak keterbukaan dan perubahan teknologi dapat mempengaruhi struktur permintaan tenaga kerja. Penelitian ini memproksi perubahan teknologi bedasarkan klasifikasi intensitas teknologi bedasarkan ketegori UNIDO. Klasifikasi industri tersebut dibagi menjadi 3 (tiga), yaitu industri berintensitas teknologi tinggi, industri berintensitas teknologi medium, dan industri berintensitas teknologi rendah. Ketika perusahaan berada di sektor berintensitas teknologi tinggi (high in technology intensity), perusahaan mengalami perubahan teknologi yang lebih tinggi dibandingkan perusahaan yang berada di sektor yang intensitas teknologi medium (medium in technology intensity) dan rendah (low in technology intensity). Lebih lanjut, hal tersebut menyebabkan kebijakan keterbukaan di negara berkembang akan lebih memperkuat perubahan teknologi pada perusahaan, terutama perusahaan yang berada di sektor yang memiliki intensitas teknologi tinggi.

Penelitian empiris FDI terhadap skill premium menunjukan perbedaan. Pertama, dampak FDI pada awalnya meningkatkan ketimpangan namun semakin lama ketimpangan akan semakin berkurang di Irlandia (Figini \& Görg, 1999). Keberadaan teknologi di perusahaan multinasional akan meningkatkan permintaan tenaga kerja ahli, sehingga menimbulkan kesenjangan antara tenaga ahli dan tidak ahli. Semakin lama perusahaan lokal berupaya meniru teknologi dari MNC sehingga tenaga kerja tidak ahli berusaha menggunakan teknologi dan menjadi tenaga kerja ahli sehingga ketidakmerataan upah menjadi kecil. Penelitian menggunakan data sektor manufaktur di Irlandia tahun 1979-1995. Ketidakmerataan upah diukur dengan perbedaan upah antara blue colar dan white colar. Ketidakmerataan dilihat dengan proporsi tenaga kerja yang bekerja di MNC, fungsi kuadrat dari proporsi tenaga keja yang bekerja di MNC, impor pada tahun sebelumnya, serta rasio tenaga kerja pada third-level education pada 3 tahun sebelumnya (pendidikan merupakan dampak jangka panjang dan menengah). Variabel dianalisis dengan data pooled yang mengasumsikan koefisien semua sektor adalah konstan.

Kedua, dampak FDI terhadap ketidakmerataan pendapatan jangka pendek lemah/ tidak signifikan sedangkan pada jangka panjang menunjukan dampak yang signifikan (Taylor \& Driffield, 2005). Penelitian data panel di 48 negara US pada 1977-2001 menunjukan 27 negara menunjukan dampak FDI menurunkan ketidakmerataan, sedangkan 21 negara menunjukan sebaliknya yaitu dampak FDI justru meningkatkan ketidakmerataan. Penelitian menggunakan variabel FDI/GDP pada tahun ke-1, ke-2, dan ke-3 untuk mengetahui dampak jangka panjang dari FDI yang dianalisis dengan ECM. Dari 48 negara yang diteliti, dampak FDI terhadap ketidakmerataan berbeda-beda.

Ketiga, hasil empiris Te Velde \& Morrissey (2004), dampak FDI terhadap ketimpangan upah clear di thailand tetapi tidak clear di Hongkong, Singapura, Filipina, dan Korea. Studi empiris dampak FDI terhadap upah telah dilakukan melalui data panel dari ILO, menggunakan dari 5 negara (Hong Kong, Korea, Singapura, Philippina dan Thailand) pada tahun 1985-1997. Dampak FDI terhadap upah relatif (upah tenaga kerja ahli terhadap upah tenaga kerja tidak ahli) diukur dengan pooled data dan fixed effect. Estimasi pooled data menunjukan bahwa FDI tidak signifikan mempengaruhi upah tenaga kerja relatif. Bedasarkan estimasi fixed effect, FDI menunjukan dampak yang berbeda. FDI di negara Hong Kong dan Philippina berpengaruh negatif dan signifikan terhadap upah relatif. Adanya FDI dapat menurunkan ketimpangan upah. FDI di negara Thailand berpengaruh positif dan signifikan terhadap 
upah relatif tenaga kerja. Adanya FDI yang tinggi menyebabkan ketimpangan upah yang besar. FDI di negara Korea dan Singapura tidak signifikan memengaruhi upah.

Terakhir, dampak FDI pada awalnya meningkatkan ketimpangan namun semakin lama ketimpangan akan semakin berkurang (Figini \& Görg, 1998). Keberadaan teknologi di perusahaan multinasional akan meningkatkan permintaan tenaga kerja ahli, sehingga menimbulkan kesenjangan antara tenaga ahli dan tidak ahli. Semakin lama perusahaan lokal berupaya meniru teknologi dari MNC sehingga tenaga kerja tidak ahli berusaha menggunakan teknologi dan menjadi tenaga kerja ahli sehingga ketidakmerataan upah menjadi kecil. Penelitian menggunakan data sektor manufaktur di Irlandia tahun 19791995. Ketidakmerataan upah diukur dengan perbedaan upah antara blue collar dan white collar. Ketidakmerataan dilihat dengan proporsi tenaga kerja yang bekerja di MNC, fungsi kuadrat dari proporsi tenaga keja yang bekerja di MNC, impor pada tahun sebelumnya, serta rasio tenaga kerja pada third-level education pada 3 tahun sebelumnya (pendidikan merupakan dampak jangka panjang dan menengah). Variabel dianalisis dengan data pooled yang mengasumsikan koefisien semua sektor adalah konstan.

Selanjutnya, bukti empiris dampak FDI di Indonesia pada ketimpangan upah juga menunjukan perdebatan. Pertama FDI tidak mempunyai dampak siginifikan terhadap penambahan jumlah orang yang bekerja di Indonesia (Syamsudin; Anton A Setyawan, 2008). Investasi langsung yang masuk ke Indonesia ternyata tidak mampu mengatasi masalah pengagguran. Kebijakan pemerintah untuk mengundang investor asing untuk pembukaan pabrik baru ternyata tidak menyerap tenaga kerja. Studi empiris tersebut dilakukan di Indonesia dengan menggunakan data dari Asian Development Bank dengan data time series FDI tahun 1983-2004 melalui analisa model ECM. Hasil berbeda ditunjukkan oleh penelitian yang dilakukan oleh Lee \& Wie (2015). Penelitian tersebut menunjukkan bahwa semakin tinggi FDI maka terjadi peningkatan kemampuan akibat perubahan teknologi dari luar yang berdampak pada upah tenaga kerja non produksi semakin besar. Studi empiris di Indonesia dengan menggunakan data panel, 4 digit level perusahaan pada industri manufaktur di Industri Besar Sedang (IBS) - Badan Pusat Stastistik (BPS) pada tahun 2000-2009. Variabel FDI di estimasi bersama-sama dengan variabel kapital, output, R\&D, human development, export, impor melalui pooled data.

Penelitian ini menggunakan model yang digunakan dalam penelitian Charfeddine \& Mrabet (2015), yaitu :

$$
\begin{aligned}
& \ln \left(\frac{W_{s}}{W_{u}}\right)_{i, j, t} \\
& =\beta_{1} \ln \left(\frac{W_{s}}{W_{u}}\right)_{i, j, t-1}+\beta_{2} \text { dummy FDI }_{i, j, t} \\
& +\beta_{3} \text { dummy Intensitas Teknologi }_{j, t} \\
& +\beta_{4} \text { dummy FDI }_{i, j, t} \\
& * \text { dummy Intensitas Teknologi }_{\mathrm{j}, \mathrm{t}} \\
& +\beta_{5} \text { Kapital }_{\mathrm{i}, \mathrm{j}, \mathrm{t}}+\beta_{6} \text { Value Added }_{\mathrm{i}, \mathrm{j}, \mathrm{t}}+\varepsilon_{\mathrm{i}, \mathrm{j}, \mathrm{t}}
\end{aligned}
$$

i merupakan merupakan perusahaan, j industri dan $\mathrm{t}$ waktu. Variabel $\frac{\mathrm{W}_{\mathrm{s}}}{\mathrm{w}_{\mathrm{u}}}$ merupakan skill premium, yang diukur dengan rasio pengeluaran tenaga kerja ahli terhadap pengeluaran tenaga kerja tidak ahli yang diukur dengan pada level perusahaan. Penelitian menggunakan lag variabel dependent sebagai variabel independent. Hal tersebut dikarenakan menurut perusahaan membutuhkan penyesuaian dalam menghadapi shok akibat keterbukaan perdagangan (Charfeddine \& Mrabet, 2015). Koefisin $\beta_{1}$ diprediksi positif karena perusahaan membutuhkan waktu menyesuaikan biaya tenaga kerja sebagai akibat dari perubahan biaya akibat kebijakan keterbukaan perdagangan.

Variable FDI diukur oleh persentase modal perusahaan yang berasal dari asing. Terinspirasi oleh Meschi et al. (2011) Keterbukaan perdagangan diukur dengan FDI yang diukur melalui dummy investasi asing. 
Ketika investasi asing lebih dari sama dengan $10 \%$ diberi nilai 1 (satu). Perusahaan yang memiliki investasi asing diasumsikan memiliki teknologi yang lebih tinggi sehingga koefisien $\beta_{2}$ diprediksi positif, perusahaan yang memiliki investasi asing minimal 10 persen maka skill premiumnya akan lebih tinggi dibandingkan perusahaan yang memiliki investasi asing kurang dari 10 persen dan perusahaan yang tidak memiliki investasi asing.

Selanjutnya untuk melihat FDI terhadap skill premium pada intensitas teknologi yang berbeda, peneliti menginteraksikan variable FDI dan variable intensitas teknologi. Koefisien $\beta_{4}$ diprediksi positif, artinya ketika perusahaan mnerima investasi asinf dan perusahaan tersebut tergolong inudtri berintensitas teknoogi tinggi maka skill premiumnya lebih tinggi.
Selanjutnya koefisien variabel control $\beta_{5}$ dan $\beta_{6}$ diprediksi positif.

Peneliti mencoba melihat persentase permodalan asing bedasarkan kategori intensitas teknologi (intensitas teknologi tinggi, intensitas teknologi medium, dan intensitas teknologi rendah). Pada gambar 2 diketahui bahwa sektor yang tergolong intensitas teknologi tinggi memiliki persentase permodalan asing yang lebih tinggi, yang diikuti oleh sektor yang tergolong intensitas teknologi medium, dan sektor yang tergolong intensitas teknologi rendah. Tahun 2003-2015 dilihat bahwa modal asing di sektor berintensitas teknologi medium dan rendah hampir stabil, sedangkan industri yang berada di intensitas teknologi tinggi pada tahun 2008 dan 2014 mengalami peningkatan.



Gambar 2

Permodalan Asing Bedasarkan Intensitas Teknologi

Sumber : BPS, diolah 


\section{Hasil dan Pembahasan Analisis Deskriptif}

Data yang digunakan dalam penelitian ini adalah data panel, yaitu data yang menggabungkan antara data time series, berupa data tahunan 2003-2015, dan data cross section berupa data level perusahaan bedasarkan kode ISIC Rev-3. Penggunaan tahun penelitian tersebut dianggap telah mampu menangkap fluktuasi tarif yang terjadi. Data-data yang digunakan dalam penelitian ini bersumber dari Badan Pusat Statistik (BPS), Trade Analysis Information System (TRAINS) UNCTAD, dan United Nations Industrial Development Organization (UNIDO). Badan Pusat Statistik (BPS) memberikan informasi data untuk variabel skill premium, investasi asing, ekspor, impor output, kapital, dan value added. Selanjutnya Trade Analysis Information System (TRAINS)- UNCTAD memberikan informasi data untuk variabel tarif input. Terakhir UNIDO memberikan informasi terkait intensitas teknologi yang digunakan perusahaan.

Statistik deskriptif digunakan untuk memberikan informasi tentang jumlah observasi, rata-rata, standar deviasi, nilai minimum, dan nilai maksimum dari masingmasing variabel yang digunakan dalam penelitian ini. Penelitian ini menggunakan estimator FE-IV. Estimator tersebut dianggap lebih tepatdigunakan karena penelitian ini menggunakan lag variabel dependent sebagai variabel independent. Estimator FE-IV membutuhkan variabel instrumen dimana variabel tersebut mempengaruhi lag skill premium namun tidak mempengaruhi skill premium. Pemilihan variabel instrumen didasari oleh nilai Cragg-Donald Wald F statistic dan Kleibergen-Paap rk Wald $F$ statistic yang nilainya harus lebih tinggi dibandingkan nilai Stock-Yogo (2005). Hasil uji dapat dilihat pada table 1 di bawah ini.

Tabel 1

Statistik Deskriptif Tahun 2003-2015

\begin{tabular}{lrrrrr}
\hline Variable & Obs & Mean & Std. Dev. & Min & Max \\
\hline In_skill_premium & 237699 & .317 & .884 & -16.525 & 9.271 \\
technology & 237699 & .355 & .479 & 0 & 1 \\
dummy_FDI & 237699 & .098 & .297 & 0 & 1 \\
dummy_FDI_tech & 237699 & .056 & .23 & 0 & 1 \\
In_k & 237699 & -.151 & 1.171 & -17.971 & 14.457 \\
In_va & 237699 & 14.285 & 2.011 & 0 & 24.074 \\
tarifinput & 237699 & .029 & .04 & 0 & .435 \\
FX & 237699 & .225 & .418 & 0 & 1 \\
FM & 237699 & .227 & .419 & 0 & 1 \\
\hline
\end{tabular}

Tabel 2

Hasil Estimasi FDI terhadap Skill Premium

(1) (2)

\begin{tabular}{l}
\hline L.In_skill_prem m \\
Ln(Kapital/VA) \\
In_va
\end{tabular}

Dtechnology

Dummy_FDI

Dummy_FDI_tech

Dummy Ekspor

$\begin{array}{cc}0.09 * * * & 0.09 * * * \\ (0.022) & (0.022) \\ 0.003 & 0.00007 \\ (0.002) & (0.002) \\ 0.002 & 0.001 \\ (0.002) & (0.002) \\ 0.00005 & 0.0002 \\ (0.015) & (0.015) \\ 0.036^{*} & 0.033^{*} \\ (0.02) & (0.02) \\ -0.027 & -0.029 \\ (0.026) & (0.026) \\ & 0.031^{* * *}\end{array}$

(0.009)
(3)

$0.09 * * *$
$(0.022)$
0.0002
$(0.002)$
0.001
$(0.002)$
-0.0002
$(0.015)$
$0.035^{*}$
$(0.02)$
-0.026
$(0.026)$

(4)

\begin{tabular}{cc}
\hline $0.09 * * *$ & $0.09 * * *$ \\
$(0.022)$ & $(0.022)$ \\
0.00005 & 0.003 \\
$(0.002)$ & $(0.002)$ \\
0.002 & 0.001 \\
$(0.002)$ & $(0.002)$ \\
-0.007 & -0.007 \\
$(0.016)$ & $(0.016)$ \\
$0.035^{*}$ & $0.032^{*}$ \\
$(0.02)$ & $(0.02)$ \\
-0.026 & -0.027 \\
$(0.026)$ & $(0.026)$ \\
& $0.031^{* * *}$ \\
& $(0.009)$
\end{tabular}

(0.009) 
Jurnal Ekonomi : Journal of Economic

p-ISSN 2087-8133| e-ISSN : 2528-326X
(1)
(2)
(3)
(4)
(5)

\begin{tabular}{|c|c|c|c|c|c|}
\hline Dummy Impor & & & $\begin{array}{c}0.034 * * * \\
(0.008)\end{array}$ & & \\
\hline Tarif Input & & & & $\begin{array}{c}0.311^{* * *} \\
(0.113)\end{array}$ & $\begin{array}{c}0.315^{* * *} \\
(0.113)\end{array}$ \\
\hline Observations & 143362 & 143362 & 143362 & 143362 & 143362 \\
\hline dummy year & Yes & Yes & Yes & Yes & Yes \\
\hline
\end{tabular}

Standard errors are in parentheses

*** $p<.01, * * p<.05, * p<.1$

Dependent variable : In_skill_premium

Tabel 1 dapat diketahui bahwa perusahaan yang menerima investasi asing minimal 10 persen memiliki skill premium lebih tinggi dibandingkan perusahaan yang memiliki investasi asing lebih rendah dari 10 persen, namun dampak tersebut tidak berbeda pada perusahaan yang memiliki perbedaan intensitas teknologi (kolom 1, kolom 2, kolom 3, kolom 4 dan kolom 5). Dalam kata lain, investasi asing memiliki pengaruh pada skill premium baik perusahaan yang tergolong industri berintensitas teknologi tinggi maupun perusahaan yang tergolong industri berintensitas teknologi rendah. Hubungan positif FDI terhadap skill premium juga ditunjukkan dalam penelitian (Lee \& Wie, 2015), Masuknya FDI berkolerasi dengan transfer teknologi sehingga meningkatkan ketimpangan upah akibat peningkatan permintaan yang lebih besar terhadap tenaga kerja ahli. Transfer teknologi akibat masuknya investasi asing ternyata tidak berbeda antar intensitas sektor industri, hal tersebut dapat dilihat dari variable interaksi antara FDI dan intensitas teknologi yang menunjukkan hubungan yang tidak signifikan (table 1 hingga table 5).

Variabel lag skill premium menunjukkan hubungan positif terhadap skill premium pada table 1, table 2 tabel 3, table 4, dan table 5 . Hubungan positif tersebut menandakan bahwa peningkatan skill premium di tahun sebelumnya menyebabkan peningkatan skill premium pada tahun ini. Dampak masuknya investasi asing tidak direspon perusahaan secara langsung, perusahaan membutuhkan waktu penyesuaian dalam menghadapi perubahan kebijakan keterbukaan perdagangan sehingga skil premium tahun sebelumnya mempengaruhi skill premium pada tahun ini (Charfeddine \& Mrabet, 2015).

Pada tabel 2 peneliti memasukan variable dummy ekspor dimana perusahaan yang melakukan ekspor diberi nilai 1. Hasilnya menunjukkan bahwa dummy ekspor berpengaruh positif. Aldaba (2013) dan Charfeddine \& Mrabet (2015) berpendapat bahwa ketika negara menerapkan keterbukaan perdagangan, perusahaan memperoleh keuntungan dengan terbukanya pangsa pasar baru. Untuk meraih pangsa pasar tersebut, perusahaan menyesuaikan proses produksi dengan menggunakan teknologi yang lebih modern. Selain itu untuk meningkatkan produktivitas, perusahaan merealokasi sumberdaya dari yang kurang produktif menjadi lebih produktif dan meningkatkan kualitas produksi dengan menghasilkan produk yang mampu bersaing. Oleh karenanya, perusahaan meningkatkan permintan tenaga kerja ahli relatif lebih tinggi dibandingkan tenaga kerja tidak ahli, skill premium naik. Dummy ekspor yang positif juga ditunjukkan pada table 5 ketika peneliti mengestimasi variable utama beserta dummy ekspor dan tarif input.

Selanjutnya pada table 4, peneliti menambahkan variable dummy impor yang menunjukkan hubungan positif terhadap skill premium. Menurut Charfeddine \& Mrabet (2015), ketika negara menerapkan keterbukaan perdagangan, perusahaan memperoleh keuntungan dengan terbukanya pangsa pasar baru. Untuk meraih pangsa pasar yang tinggi, perusahaan menyesuaikan proses produksi dengan menggunakan teknologi yang lebih modern. Selain itu untuk meningkatkan produktivitas, perusahaan merealokasi sumberdaya dari yang kurang produktif 
menjadi lebih produktif dan meningkatkan kualitas produksi dengan menghasilkan produk yang mampu bersaing. Oleh karenanya, perusahaan meningkatkan permintan tenaga kerja ahli relatif lebih tinggi dibandingkan tenaga kerja tidak ahli, skill premium naik.

\section{Kesimpulan}

Penelitian ini mengestimasi dampak masuknya investasi asing terhadap skill premium ahli di Indonesia. Skill premium menarik untuk diteliti di Indonesia karena erat kaitannya ketidakmerataan pendapatan antar tipe tenaga kerja. Ketika investasi masuk berasal dari negara yang memiliki teknologi tinggi, kebijakan keterbukaan perdagangan menjadi pintu masuk perubahan teknologi. Banyaknya tenaga kerja tidak ahli dibandingkan tenaga kerja ahli menyebabkan terjadinya stuktur permintaan tenaga kerja. Untuk menjawab tujuan tersebut, penelitian ini menggunakan data panel berupa data level perusahaan periode 2003-2015 dengan fungsi produksi CES. Untuk melihat perbedaan dampak skill premium pada intensitas teknologi, peneliti membedakan perusahaan bedasarkan intensitas teknologi dalam UNIDO. Hasilnya menunjukkan bahwa dampak perusahaan yang memiliki investasi asing memiliki skill premium lebih tinggi namun dampak ini sama antar perusahaan yang berbeda intensitas teknologi.

Penelitian ini memiliki keterbatasan, yaitu hanya menganalisis untuk industri manufaktur Indonesia. Jika pembaca tertarik melakukan penelitian tentang dampak keterbukaan perdagangan dan skill premium, maka dapat melakukan analisa secara lebih konferhensif yang tidak haya menganalisis industri manufaktur tetapi juga industri lainnya. Selain itu penelitian ini juga tidak membedakan tenaga kerja bedasarkan gender (laki-laki dan perempuan) dan belum mendiskusikan kemungkinan adanya pengaruh proteksi terhadap tenaga kerja. Oleh karena itu dampak keterbukaan perdagangan belum dianalisis secara lebih spesifik bagi tenaga kerja laki-laki maupun tenaga kerja perempuan dan bagaimana dampak serikat pekerja pada masing-masing tipe tenaga kerja (tenaga kerja ahli dan tenaga kerja tidak ahli).

\section{Daftar Pustaka}

Acemoglu, D. (1998). Why do new technologies complement skills? Directed technical change and wage inequality. The Quarterly Journal of Economics, 113(4), 1055-1089. Retrieved from https://www.jstor.org/stable/2586974

Abramovitz, M. (1993). The search for the sources of growth: Areas of ignorance, old and new. The Journal of Economic History, 53(2), 217-243.

Aldaba, R. M. (2013). Impact of trade liberalization on wage skill premium in Philippine Manufacturing. In Philippine Institute for Development Studies (PIDS).

https://doi.org/http://hdl.handle.net/10 419/126920 StandardNutzungsbedingungen:

Bandick, R., \& Hansson, P. (2009). Inward FDI and demand for skills in manufacturing firms in Sweden. 111-131. https://doi.org/10.1007/s10290-0090002-9

Berman, E., Somanathan, R., \& Tan, H. W. (2003). Is skill bias technological change here yet? Evidence from Indian manufacturing in the 1990. World Bank Working Paper. Retrieved from http://www.nber.org/CRIW/papers/ber man.pdf

Charfeddine, L., \& Mrabet, Z. (2015). Trade liberalization and relative employment: further evidence from Tunisia. Eurasian Business Review, 5(1), 173-202.

Feenstra, R. C., \& Hanson, G. H. (2005). Ownership and control in outsourcing to China: estimating the property-rights theory of the firm. Quarterly Journal of Economics, 120(2), 729-761. Retrieved from

https://www.jstor.org/stable/25098751

Figini, P., \& Görg, H. (1998). Multinational Companies and Wage Inequality in the Host Country: The Case of Ireland. 98. http://citeseerx. ist.psu.edu/viewdoc/do 
wnload?doi=10.1.1.492.9130\&rep=rep1 \&type $=p d f$

Goldberg, P. K., \& Pavcnik, N. (2007). Distributional Effects of Globalization in Developing Countries. Journal of Economic Literature, 45(1), 39-82. https://doi.org/10.1257/jel.45.1.39.

Hayami, Y., \& Godo, Y. (2005). Development economics from the poverty to wealth of nations (Third Edit). Oxford University Press.

Kokko, A., Zejan, M., \& Tansini, R. (2001). Trade regimes and spillover effects of FDI: Evidence from Uruguay. Weltwirtschaftliches Archiv, 1372001), 124-149.

Lee, J., \& Wie, D. (2015). Technological Change, Skill Demand, and Wage Inequality: Evidence from Indonesia. WORLD DEVELOPMENT, 67, 238-250. https://doi.org/10.1016/j. worlddev.201 4.10.020

Lipsey, Robert E, \& Sjoholm, F. (2004). Foreign direct investment, education and wages in Indonesian manufacturing. Journal of Development Economics, 73, 415-422. https://doi.org/10.1016/j.jdeveco.2002. 12.004

Marin, A., \& Bell, M. (2007). Technology spillovers from Foreign Direct Investment (FDI): The active role of MNC subsidiaries in Argentina in the 1990s. Journal of Development Studies, 42(4), 678-697. https://doi.org/10.1080/002203806006 82298

Meschi, E., Taymaz, E., \& Vivarelli, M. (2011). Trade, technology and skills: evidence from Turkish microdata. Labour Economics, 18, S60-S70. https://doi.org/10.1016/j.labeco.2011.0 7.001

Syamsudin; Anton A Setyawan. (2008). FOREIGN DIRECT INVESTMENT ( FDI), KEBIJAKAN INDUSTRI , DAN MASALAH PENGANGGURAN: STUDI EMPIRIK. Jurnal Ekonomi Dan Pembangunan Indonesia, 9(1).
Taylor, K., \& Driffield, N. (2005). Wage inequality and the role of multinationals: evidence from UK panel data. 12, 223-249. https://doi.org/10.1016/j.labeco.2003.1 1.003

Te Velde, D. W., \& Morrissey, O. (2004). Foreign direct investment, skills, and wage inequality in East Asia. Journal of the Asia Pacific Economy, 9(3), 348369.

https://doi.org/10.1080/135478604200 0272991 